\title{
Investigating Intestinal Permeability of Bortezomib Using a Validated HPLC-UV Method
}

\section{Authors}

Mohammad Mahmoudian', 2, Parvin Zakeri-Milani ${ }^{3}$, Hadi Valizadeh4

\section{Affiliations}

1 Student Research Committee, Tabriz University of Medical Sciences, Tabriz, Iran

2 Biotechnology Research Center and Faculty of Pharmacy, Tabriz University of Medical Sciences, Tabriz, Iran

3 Liver and Gastrointestinal Diseases Research Center and Faculty of Pharmacy, Tabriz University of Medical Sciences, Tabriz, Iran

4 Drug Applied Research Center and Faculty of Pharmacy, Tabriz University of Medical Sciences, Tabriz, Iran

\section{Key words}

bortezomib, intestinal permeability, HPLC

received 09.04.2017

accepted $\quad 04.07 .2017$

\section{Bibliography}

DOI https://doi.org/10.1055/s-0043-115648

Published online: 16.11.2018

Drug Res 2019; 69: 130-135

(c) Georg Thieme Verlag KG Stuttgart · New York ISSN 2194-9379

\section{Correspondence}

Hadi Valizadeh

Drug Applied Research Center and Faculty of Pharmacy

Tabriz University of Medical Sciences

University Street

51664 Tabriz,

Iran

Tel.: + 98/41/3339 2649, Fax: + 98/41/3334 479

valizadeh@tbzmed.ac.ir

\section{ABSTRACT}

Bortezomib (BTZ), as a proteasome inhibitor, has been used for treatment of patients with relapsed/refractory multiple myeloma and mantle cell lymphoma. BTZ is available for intravenous injection or subcutaneous administration. In this study, for evaluating the potential of BTZ oral delivery, intestinal permeability of BTZ was determined using in situ single-pass intestinal perfusion (SPIP) technique and the perfused solutions were analyzed using a validated HPLC-UV method. The chromatographic separation was performed using a C18 column via isocratic mode at a flow rate of $0.5 \mathrm{~mL} / \mathrm{min}$ at $270 \mathrm{~nm}$. The mobile phase was a mixture of methanol/deionized water $(50: 50 \% \mathrm{v} / \mathrm{v})$ with $0.1 \%$ glacial acetic acid. The results indicated that calibration curves were linear $\left(r^{2}>0.99\right)$ in a concentration range of $1.65-5 \mu \mathrm{g} / \mathrm{mL}$ for BTZ and $8.33-25 \mu \mathrm{g} / \mathrm{mL}$ for phenol red. A limit of quantitation of 1.03 and $6.67 \mu \mathrm{g} / \mathrm{mL}$ was obtained for BTZ and phenol red, respectively. The recovery values were in the range of $96.5-105.4 \%$ for BTZ, and 88$99.2 \%$ for phenol red. The relative standard deviations (RSD) were $\leq 4.9 \%$ for BTZ and $\leq 7 \%$ for phenol red. Stability studies indicated that the working standard solution is stable over a period of $48 \mathrm{~h}$ at room temperature. Finally, an effective permeability $\left(P_{\text {eff }}\right)$ value of $(3.36 \pm 0.5) \times 10^{-5} \mathrm{~cm} / \mathrm{sec}$ (mean \pm SEM) was achieved for BTZ. Moreover, it was predicted that BTZ belongs to the biopharmaceutical class III.

\section{Introduction}

Proteasomes are intracellular protein complexes which play an important role in the cell division and apoptosis by degradation of ubiquitinated regulatory proteins. Aberrant degradation of regulatory proteins through ubiquitin-proteasome pathway, can lead to uncontrolled cell proliferation and cause tumor formation and metastasis [1-3]. In vitro and in vivo studies showed that proteasome inhibitors can induce apoptosis in cancer cells and inhibit tumor growth [4-8]. Thus, proteasome inhibitors have been considered as anticancer drugs in cancer treatment.
Bortezomib (BTZ; > Fig. 1) is the first proteasome inhibitor approved by the US food and drug administration (FDA) for treatment of patients with relapsed/refractory multiple myeloma and mantle cell lymphoma. BTZ is given twice weekly for 2 weeks followed by 1 week rest period (21-day cycles), and is available for intravenous injection or subcutaneous administration [9-11].

In this study, for evaluating the potential of BTZ oral delivery, the intestinal permeability of BTZ was measured. Oral chemotherapy can improve the quality of life in cancer patients, reduce the cost of treatment and provide an easy way to chemotherapy as compared with i.v administration [12-15]. 
<smiles>CC(C)C[C@H](NC(=O)[C@H](Cc1ccccc1)NC(=O)c1cnccn1)B(O)O</smiles>

- Fig. 1 Chemical structure of bortezomib (BTZ); the ([3-methyl1-(3-phenyl-2-pyrazin-2-ylcarbonylamino-propanoyl) amino-butyl] boronic acid.

The aim of this study, was to evaluate the intestinal permeability of BTZ. Intestinal permeability is an important factor that influence the bioavailability of orally delivered drugs [16-18]. Therefore, the results of this study, can give us new aspects for oral delivery of BTZ. Moreover, biopharmaceutical class of BTZ can be predicted.

The intestinal permeability of BTZ was measured by in situ single-pass intestinal perfusion (SPIP) model in rat. In the SPIP technique, a solution of respected drug is perfused through an intestinal segment in anesthetized animals $[19,20]$. A non-absorbable marker, phenol red, is added to the perfusion solution for determining the water secretion or absorption in intestinal wall [21, 22].

A simple HPLC-UV method was validated according to the International Conference on Harmonization (ICH) guidelines on bioanalytical method validation for simultaneous quantification of BTZ and phenol red in the perfused samples [23].

\section{Materials}

Bortezomib and phenol red was obtained from Sigma-Aldrich (St. Louis, MO, USA). Sodium pentobarbital was provided from Kela (Hoogstraten, Belgium). Methanol was HPLC grade and purchased from Ameretat Shimi (Mamounyeh Ind., Iran). $\mathrm{Na}_{2} \mathrm{HPO}_{4}$ (anhydrous), $\mathrm{NaH}_{2} \mathrm{PO}_{4} \cdot 2 \mathrm{H}_{2} \mathrm{O}, \mathrm{NaCl}, \mathrm{NaOH}$ and glacial acetic acid were obtained from Merck (Darmstadt, Germany). Double distilled water was used during the study.

\section{Methods}

\section{Animals}

3 Male Wistar rats, $180-250 \mathrm{~g}$, were used in perfusion studies. All animals were fasted $24 \mathrm{~h}$ with free access to water before experiments. In all animal studies "Guide to the care and use of experimental animals" by Canadian Council on Animal Care, was followed [24].

\section{Instrumentation}

A liquid chromatographic system (Knauer-Smartline, Germany) comprising of; manager 5000, pump 100 and UV detector 2500, with a C18 (Varian-Polaris $5100 \times 2.1 \mathrm{~mm}$ ) column was used for chromatographic separations. System EZChrom Elite software was used for data acquisition, reporting and analysis.

\section{Chromatographic conditions}

The mobile phase was a mixture of methanol/deionized water (50:50\% v/v) with $0.1 \%$ glacial acetic acid and degassed for $10 \mathrm{~min}$ with an ultrasonic bath. A $50 \mu \mathrm{L}$ sample was injected into the column and analyzed in an isocratic mode at a flow rate of $0.5 \mathrm{~mL} / \mathrm{min}$ at ambient temperature. The HPLC chromatograms monitored at $270 \mathrm{~nm}$.

\section{Preparation of stock, perfusion and working stand- ard solutions}

Prior to preparation of perfusion and working standard solutions, a stock solution of BTZ (methanol, $4000 \mu \mathrm{g} / \mathrm{mL}$ ) and phenol red $\left(\mathrm{PBS}, 500 \mu \mathrm{g} / \mathrm{mL}\right.$ ) was prepared and kept at $4{ }^{\circ} \mathrm{C}$. A perfusion solution that consisted of BTZ $(10 \mu \mathrm{g} / \mathrm{mL})$ and phenol red $(50 \mu \mathrm{g} / \mathrm{mL})$ was prepared using a suitable volume of the stock solution which was reached to a proper volume in a volumetric flask with PBS $\left(37^{\circ} \mathrm{C}\right)$. BTZ concentration in perfusion solution was selected on the basis of BTZ human dose $\left(1.3 \mathrm{mg} / \mathrm{m}^{2}\right)$. Dose is equally related to the body weight although it is not the alone factor which influences the scaling for dose calculation. The correction factor $\left(K_{m}\right)$ is estimated by dividing the average body weight $(\mathrm{kg})$ of species to its body surface area $\left(\mathrm{m}^{2}\right)$ which are available in the literature. The following equation was used for equivalent dose calculation:

$$
\begin{aligned}
& \text { Human dose }(\mathrm{mg} / \mathrm{kg})= \\
& \quad \text { Rat dose }(\mathrm{mg} / \mathrm{kg}) \times\left(\text { Rat } \mathrm{K}_{\mathrm{m}} / \text { Human } \mathrm{K}_{\mathrm{m}}\right)
\end{aligned}
$$

where human dose is $0.035 \mathrm{mg} / \mathrm{kg}$ for $\mathrm{BTZ}$, rat $\mathrm{K}_{\mathrm{m}}$ is 6 and human $K_{m}$ is 37 . Therefore, assuming the $4 \mathrm{~mL}$ volume of fasted rat GIT content, the Dose $10.7 \mu \mathrm{g} / \mathrm{mL}$ is achieved for BTZ administration in rats. We have used $10 \mu / \mathrm{mL}$ in perfusion solution. The perfusion buffer consisted of $\mathrm{Na}_{2} \mathrm{HPO}_{4}$ (anhydrous, $5.77 \mathrm{~g} / \mathrm{L}$ ), $\mathrm{NaH}_{2} \mathrm{PO}_{4} .2 \mathrm{H}_{2} \mathrm{O}(4.08 \mathrm{~g} / \mathrm{L})$ and $\mathrm{NaCl}(7 \mathrm{~g} / \mathrm{L})$, adjusted to $\mathrm{pH} 7.2$ with sodium hydroxide solution. The perfusion solution was diluted with PBS to make working standard solutions with concentrations of $1.65,2.5,3.3,4$, and $5 \mu \mathrm{g} / \mathrm{mL}$ for BTZ and $8.3,12.5,16.6,20$, and $25 \mu \mathrm{g} / \mathrm{mL}$ for phenol red.

\section{Method validation}

The HPLC method was validated for linearity, limit of detection and quantitation, precision, accuracy and stability according to the ICH guidelines on bioanalytical method validation [23].

\section{Linearity}

Linearity of the method was evaluated by plotting the peak area vs. concentration for calibration curves, over 3 consecutive days in triplicate. The least-square method was used for linear regression analysis.

\section{Limit of detection (LOD) and quantitation (LOQ)}

The LOD and LOQ for BTZ and phenol red were calculated using Eq. (2):

$\operatorname{LOD}$ or $L O Q=A\left(S D_{y \text {-intercept }} / S\right)$ 
where A, the signal to noise ratio, is 3 for LOD and 10 for LOQ, $\mathrm{SD}_{y}$-intercept is the standard deviation of $y$-intercept, and $\mathrm{S}$ is the mean value of slope for calibration curves $[25,26]$.

\section{Precision and accuracy}

Precision demonstrates a scattering degree between acquired data from a multiple evaluation of the same sample and is expressed as the relative standard deviation (RSD). Accuracy represents the closeness between the found and reference values and is expressed as the recovery. The precision and accuracy of the method were determined by analyzing 3 standard working solutions with concentrations of $2.5,3.3$, and $4 \mu \mathrm{g} / \mathrm{mL}$ for BTZ and $12.5,16.6$, and $20 \mu \mathrm{g} / \mathrm{mL}$ for phenol red, over 3 consecutive days.

\section{Short-term stability study}

Short-term stability study was performed to ensure that drug concentration declining in the perfusion solution is due to the intestinal permeability not to the stability problems. The stability study was conducted by analyzing the working standard solution at concentration of $3.3 \mu \mathrm{g} / \mathrm{mL}$ for BTZ and $16.6 \mu \mathrm{g} / \mathrm{mL}$ for phenol red over a period of $48 \mathrm{~h}$. The samples were kept at room temperature and analyzed at beginning, $24 \mathrm{~h}$ and $48 \mathrm{~h}$.

\section{System suitability tests}

System suitability tests are conducted to ensure the adequacy of the HPLC system for the sample analysis. Capacity factor $\left(k^{\prime}\right)$, selectivity factor $(\alpha)$, resolution $(R)$, tailing factor $(T)$, number of theoretical plates per column ( $\mathrm{N})$, and dead volume are parameters that calculated in system suitability evaluation using USP guidelines.

\section{In situ single-pass intestinal perfusion (SPIP) studies}

Animal investigations were approved locally by the Ethics Committee of the Tabriz University of Medical Sciences (Tabriz, Iran) with an identification code number of TBZMED.REC.1394.255. The intestinal permeability of BTZ was evaluated using SPIP model as reported previously [27-29]. Briefly, rats were anaesthetized using an intraperitoneal injection of sodium pentobarbital $(60 \mathrm{mg} / \mathrm{kg})$ and placed on a heated pad under a surgical lamp. The abdomen was opened by making a midline incision and a jejunal segment (approximately $25 \mathrm{~cm}$ away from pylorus and a length of $10 \mathrm{~cm}$ ) was cannulated with plastic tubes ( $3 \mathrm{~mm}$ o.d.). The inlet tube was connected to a syringe $(60 \mathrm{~mL})$ which was placed in an infusion pump (Palmer, UK). The entire surgical area was covered with a wetted-sterile gauze and parafilm to reduce moisture loss. The solution was perfused at a flow rate of $1 \mathrm{~mL} / \mathrm{min}$ for $10 \mathrm{~min}$, to remove intestinal debris and to reach a steady-state concentration for BTZ across the intestinal wall. Then, the flow rate was set at $0.2 \mathrm{~mL} / \mathrm{min}$ and outlet solution was collected at 10 min intervals and kept at $4{ }^{\circ} \mathrm{C}$. At the end of the experiments, the location and length of the intestinal segment was determined. The effective permeability $\left(\mathrm{P}_{\text {eff }}\right)$ of BTZ was calculated according to the "parallel-tube" model that expressed by Eq. (3):

$P_{\text {eff }}=\left[-Q \ln \left(C_{\text {out (corr) }} / C_{\text {in }}\right)\right] / 2 \pi r L$

where $Q$ is the rate of infusion $(0.2 \mathrm{~mL} / \mathrm{min}), r$ is the radius of the intestinal segment $(0.18 \mathrm{~cm}), \mathrm{L}$ is the length of the intestinal seg- ment $(\mathrm{cm}), C_{\text {in }}$ is the inlet concentration $(\mu \mathrm{g} / \mathrm{mL})$ of BTZ, $C_{\text {out(corr) }}$ is the outlet concentration $(\mu \mathrm{g} / \mathrm{mL})$ of BTZ which was corrected for water flux according to the Eq. (4):

$C_{\text {out (corr) }}=\left(C_{\text {phenol red (in) }} / C_{\text {phenol red (out) }}\right) C_{\text {out }}$

where $C_{\text {out }}$ is the outlet concentration $\left(\mu \mathrm{g} / \mathrm{mL}\right.$ ) of $B T Z, C_{\text {phenol red (in) }}$ and $C_{\text {phenol red (out) }}$ are the inlet and outlet concentrations $(\mu \mathrm{g} / \mathrm{mL})$ of phenol red, respectively. The $P_{\text {eff }}$ value was expressed as mean \pm standard error of mean (SEM) for 3 experiments.

\section{HPLC analysis of the perfused solutions}

The collected samples were filtered through a syringe filter (CA $0.2 \mu \mathrm{m}$ ) and analyzed by the proposed HPLC method after dilution with methanol/PBS $(50: 50 \% \mathrm{v} / \mathrm{v})$ at a ratio of $1: 2$.

\section{Biopharmaceutical class of BTZ}

According to previously published study by Zakeri-Milani et al. [30], biopharmaceutical class of BTZ was predicted based on the $P_{\text {eff }}$ and dose number $\left(D_{0}\right)$. $D_{0}$ is a criterion for solubility and is calculated using Eq. (5):

$D_{0}=\left(M / V_{0}\right) / C_{s}$

where $M$ is the maximum dose strength ( $3.5 \mathrm{mg}$ for $B T Z$ ), $V_{0}$ is the volume of water taken with the dose (generally set to be $250 \mathrm{~mL}$ ) and $C_{S}$ is the solubility of drug, which was considered $3.3 \mathrm{mg} / \mathrm{mL}$ for BTZ [31].

\section{Results and Discussion}

In this study, for evaluating the potential of BTZ oral delivery, the intestinal permeability of BTZ was determined using the SPIP technique. Phenol red, as a non-absorbable marker, was added to the perfusion solution to correct the effect of water flux on the concentration of perfused-drug. Simultaneous quantification of BTZ and phenol red can be time saving for sample analysis. For this, a simple HPLC-UV was conducted. The chromatograms of the drug containing and drug-free perfusion solutions represent no interfering peak ( $>$ Fig. 2). A short retention time of 1.45 and 2.96 min was observed for phenol red and BTZ. The method was more validated for the linearity, accuracy, precision and also short-term stability study was performed.

\section{Linearity}

Linearity of the method was assessed by constructing 5-point calibration curves on 3 consecutive days in replicate $(n=3)$. Regression parameters (slope, $y$-intercept and determination coefficient) were determined using least-square method. The regression data were listed in > Table 1, and indicate a linearity with a determination coefficient greater than 0.99 .

\section{Limit of detection (LOD) and quantitation (LOQ)}

The LOD value of 0.18 and $3.45 \mu \mathrm{g} / \mathrm{mL}$ was obtained for BTZ and phenol red, respectively. Moreover, the LOQ value of 1.03 and $6.67 \mu \mathrm{g} / \mathrm{mL}$ was achieved for BTZ and phenol red, respectively. 

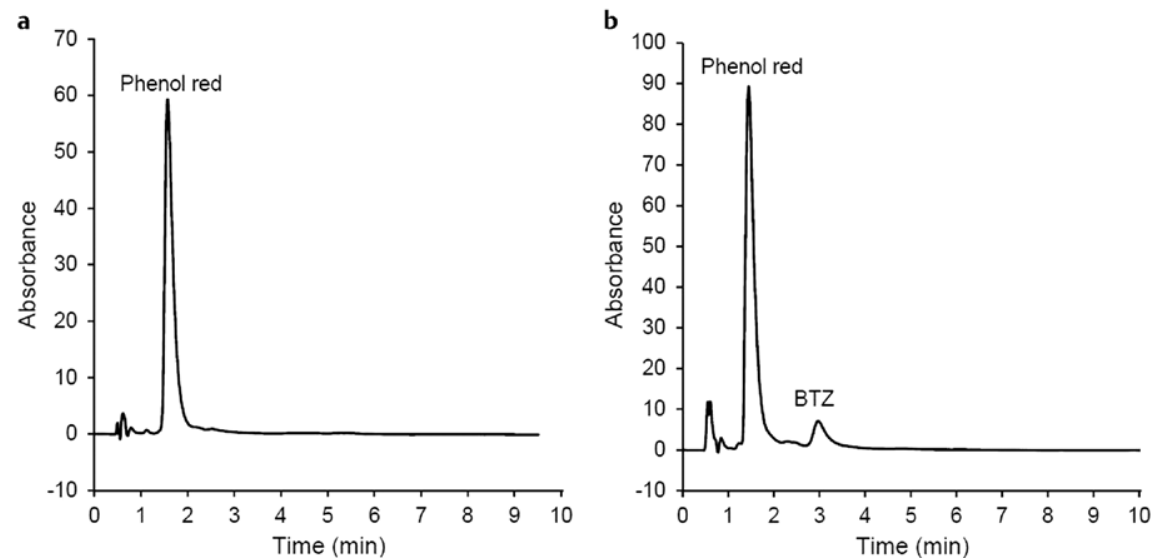

- Fig. 2 A typical chromatogram of; a drug-free perfusion medium, and b perfused solution (consisted of $10 \mu \mathrm{g} / \mathrm{mL}$ BTZ and $50 \mu \mathrm{g} / \mathrm{mL} \mathrm{phenol}$ red).

- Table 1 Regression analysis of calibration curves for bortezomib and phenol red.

\begin{tabular}{|l|l|l|}
\hline Parameter & Bortezomib & Phenol red \\
\hline Range $(\mu \mathrm{g} / \mathrm{mL})$ & $1.65-5.00$ & $8.33-25.00$ \\
\hline Slope & 69117 & 73539.7 \\
\hline Intercept & 16918.3 & -99642 \\
\hline Determination Coefficient $\left(\mathrm{r}^{2}\right)$ & 0.994 & 0.991 \\
\hline
\end{tabular}

\section{Precision and accuracy}

Accuracy and precision of the method were determined by analyzing 3 quality control samples. The concentrations were selected based on the obtained LOD and LOQ values for BTZ and phenol red. Intraday and interday precision and accuracy data were summarized in $>$ Table 2 . The intraday precision values were $\leq 4.9 \%$ for $\mathrm{BTZ}$, and $\leq 7 \%$ for phenol red while the interday precision values were $\leq 1.8 \%$ for BTZ, and $\leq 1.9 \%$ for phenol red. The values obtained for intraday accuracy were within $96.5-105.4 \%$ for BTZ, and $92-99.2 \%$ for phenol red. However, interday accuracy values were in the range of $100-101.2 \%$ for BTZ, and $88-98.6 \%$ for phenol red. According to the ICH guidelines, recovery and RSD criteria on bioanalytical method validation should be within $\pm 15 \%$. Thus, the precision and accuracy values of the method are within the recommended limit.

\section{Stability}

Short-term stability of working standard solution, at a nominal concentration of $3.33(\mu \mathrm{g} / \mathrm{mL})$ for BTZ and $16.66(\mu \mathrm{g} / \mathrm{mL})$ for phenol red, was determined over a period of $48 \mathrm{~h}$ at room temperature. The mean measured concentrations were summarized in $>$ Table 3. Variation in the concentration was $<1 \%$ for BTZ, and $\leq 4.5 \%$ for phenol red over a period of $48 \mathrm{~h}$. The stability of solution is acceptable when variation in the concentration will be $\pm 15 \%$. Therefore, the working standard solution is stable over a period of $48 \mathrm{~h}$ at room temperature.

\section{System suitability tests}

System suitability tests were performed according to the USP guidelines. Capacity factor was measured as 1.41 and 3.93 for phenol red and BTZ, respectively. Selectivity factor was obtained 2.78 , and resolution value achieved 1.95 for separation of phenol red and BTZ (R should be $>1.5$ ). For evaluating the asymmetry of the peaks, tailing factors were determined 1.83 for phenol red, and 1.71 for BTZ (recommended limit for $T$ is $\leq 2$ ). Number of theoretical plates per column was calculated as 53 for phenol red and 250 for BTZ. Meanwhile, a dead volume of $0.3 \mathrm{~mL}$ was determined from the chromatogram. The system suitability data indicated a compliance for the HPLC system.

\section{Intestinal permeability and biopharmaceutical class of BTZ}

In this study, biopharmaceutical class of BTZ was predicted based on the obtained rat $P_{\text {eff }}$ and $D_{0}$ according to previously published study by Zakeri-Milani et al. [30]. ₹ Table 4, represents the borderlines of $P_{\text {eff }}$ and $D_{0}$ for different drug classes. $A P_{\text {eff }}$ value (mean $\pm S E M$ ) of $(3.36 \pm 0.5) \times 10^{-5} \mathrm{~cm} / \mathrm{sec}$ was achieved for $\mathrm{BTZ}$, and $\mathrm{D}_{0}$ was calculated as 0.004 . Therefore, by considering these data it seems that BTZ belongs to the third biopharmaceutical class (High solubility, low permeability). On the other hand, the human intestinal permeability of BTZ was predicted based on the correlation found between human and rat intestinal permeability values which was published by the same authors ( $P_{\text {eff (human) }}=11.04 \mathrm{P}_{\text {eff }(\text { rat })}-0.0003$; $\mathrm{R} 2=0.93, \mathrm{P}<0.0001)[32]$. Using this equation, $\mathrm{BTZ}$ human $\mathrm{P}_{\mathrm{eff}}$ is predicted to be $9.3 \times 10^{-5} \mathrm{~cm} / \mathrm{s}$, confirming its low intestinal permeability and consequently low oral absorption in human. That means for its adequate and reproducible absorption following oral administration of BTZ, various formulation strategies have to be adopted. For example, a variety of lipid-based formulations (selfemulsifying systems, mixed micelles, liposomes, solid lipid nanoparticles, and etc.) could be used to enhance BTZ intestinal permeability and subsequent oral bioavailability. 
- Table 2 Intraday and inerday accuracy and precision analysis of the HPLC method for bortezomib and phenol red.

\begin{tabular}{|c|c|c|c|c|c|c|c|}
\hline & \multirow[b]{2}{*}{$\begin{array}{c}\text { Nominal } \\
\text { Concentration }(\mu \mathrm{g} / \mathrm{mL})\end{array}$} & \multicolumn{3}{|c|}{ Intraday Measured Concentration } & \multicolumn{3}{|c|}{ Interday Measured Concentration } \\
\hline & & $\begin{array}{c}\text { Mean } \\
(\mu \mathrm{g} / \mathrm{mL})\end{array}$ & $\begin{array}{l}\text { RSD } \\
(\%)\end{array}$ & $\begin{array}{c}\text { Recovery } \\
(\%)\end{array}$ & $\begin{array}{c}\text { Mean } \\
(\mu \mathrm{g} / \mathrm{mL})\end{array}$ & $\begin{array}{l}\text { RSD } \\
(\%)\end{array}$ & $\begin{array}{c}\text { Recovery } \\
(\%)\end{array}$ \\
\hline \multirow{3}{*}{ Bortezomib } & 2.50 & 2.56 & 4.9 & 102.7 & 2.53 & 1.3 & 101.2 \\
\hline & 3.33 & 3.48 & 2.1 & 105.4 & 3.40 & 0.3 & 100.0 \\
\hline & 4.00 & 3.86 & 3.0 & 96.5 & 4.00 & 1.8 & 100.1 \\
\hline \multirow{3}{*}{ Phenol red } & 12.50 & 11.98 & 7.0 & 95.8 & 11.01 & 1.9 & 88.0 \\
\hline & 16.66 & 16.48 & 0.8 & 99.2 & 15.84 & 0.4 & 95.4 \\
\hline & 20.00 & 18.41 & 3.8 & 92.0 & 19.72 & 1.4 & 98.6 \\
\hline
\end{tabular}

- Table 3 Stability of working standard solution containing bortezomib and phenol red over a period of $48 \mathrm{~h}$ at room temperature.

\begin{tabular}{|l|c|c|c|c|c|c|}
\hline & \multicolumn{3}{|c|}{ Bortezomib } & \multicolumn{3}{c|}{ Phenol red } \\
\cline { 2 - 7 } & $\mathbf{0 h}$ & $\mathbf{2 4 h}$ & $\mathbf{4 8 h}$ & $\mathbf{0 h}$ & $\mathbf{2 4} \mathbf{h}$ & $\mathbf{4 8 h}$ \\
\hline Mean Measured Concentration $(\mathrm{\mu g} / \mathrm{hL})$ & 3.48 & 3.49 & 3.45 & 17.07 & 16.31 & 16.98 \\
\hline RSD $(\%)$ & 2.1 & 6.5 & 1.7 & 0.7 & 6.1 & 1.5 \\
\hline Percent of Initial Concentration $(\%)$ & - & 100.4 & 99.3 & - & 95.5 & 99.4 \\
\hline
\end{tabular}

- Table 4 The borderlines of effective intestinal permeability $\left(P_{\text {eff }}\right)$ value in rat and dose number $\left(D_{0}\right)$, for different drug classes.

\begin{tabular}{|l|c|c|}
\hline Class & $\mathbf{P}_{\text {eff }}\left(\times \mathbf{1 0}^{-\mathbf{5}} \mathbf{~} \mathbf{m} / \mathbf{s}\right)$ & $\mathbf{D}_{\mathbf{o}}$ \\
\hline I & $>5.09$ & $<0.5$ \\
\hline II & $>5.09$ & $<1$ \\
\hline III & $<4.2$ & $<0.5$ \\
\hline IV & $<4.2$ & $<1$ \\
\hline \multicolumn{2}{|l|}{ aData was collected from Ref. [30]. } \\
\hline
\end{tabular}

\section{Conclusion}

In this study, the intestinal permeability of BTZ was evaluated using SPIP technique. A $P_{\text {eff }}$ value (mean \pm SEM) of $(3.36 \pm 0.5) \times$ $10^{-5} \mathrm{~cm} / \mathrm{s}$ was obtained for BTZ. Moreover, it was predicted that BTZ belongs to the third biopharmaceutical class (High solubility, low permeability).

\section{Acknowledgments}

The financial support from the "Drug Applied Research Center", Tabriz University of Medical Sciences is greatly acknowledged. This paper is based on a PhD thesis (Dissertation number: 108) submitted by Mohammad Mahmoudian in Faculty of Pharmacy, Tabriz University of Medical Sciences.

\section{Conflict of interest}

The authors declare that there are no conflicts of interest.

\section{References}

[1] Adams J. The proteasome: A suitable antineoplastic target. Nature Reviews Cancer. 2004; 4: 349-360

[2] Adams J, Palombella V], Sausville EA et al. Proteasome inhibitors: A novel class of potent and effective antitumor agents. Cancer Research. 1999; 59: 2615-2622
[3] Orlowski RZ, Kuhn DJ. Proteasome inhibitors in cancer therapy: Lessons from the first decade. Clinical Cancer Research. 2008; 14: 1649-1657

[4] LeBlanc R, Catley LP, Hideshima T et al. Proteasome inhibitor PS-341 inhibits human myeloma cell growth in vivo and prolongs survival in a murine model. Cancer Research. 2002; 62: 4996-5000

[5] Sunwoo JB, Chen Z, Dong G et al. Novel proteasome inhibitor PS-341 inhibits activation of nuclear factor-кB, cell survival, tumor growth, and angiogenesis in squamous cell carcinoma. Clinical Cancer Research. 2001; 7: 1419-1428

[6] Shah SA, Potter MW, McDade TP et al. 26S proteasome inhibition induces apoptosis and limits growth of human pancreatic cancer. Journal of Cellular Biochemistry. 2001; 82: 110-122

[7] Frankel A, Man S, Elliott P et al. Lack of multicellular drug resistance observed in human ovarian and prostate carcinoma treated with the proteasome inhibitor PS-341. Clinical Cancer Research. 2000; 6: 3719-3728

[8] Imajohohmi S, Kawaguchi T, Sugiyama S et al. Lactacystin, a specific inhibitor of the proteasome, induces apoptosis in human monoblast U937 cells. Biochemical and Biophysical Research Communications 1995; 217: 1070-1077

[9] Chen D, Frezza M, Schmitt S et al. Bortezomib as the first proteasome inhibitor anticancer drug: Current status and future perspectives. Current Cancer Drug Targets. 2011; 11: 239

[10] Bold R. "Development of the Proteasome Inhibitor Velcade $^{\mathrm{TM}}$ (Bortezomib)” by Julian Adams, Ph. D., and Michael Kauffman, MD, Ph. D. Cancer Investigation 2004; 22: 328-329

[11] Pennisi A, Li X, Ling W et al. The proteasome inhibitor, bortezomib suppresses primary myeloma and stimulates bone formation in myelomatous and nonmyelomatous bones in vivo. American Journal of Hematology. 2009; 84: 6-14

[12] Mazzaferro S, Bouchemal K, Ponchel G. Oral delivery of anticancer drugs I: general considerations. Drug Discovery Today. 2013; 18: 25-34

[13] Mei L, Zhang Z, Zhao L et al. Pharmaceutical nanotechnology for oral delivery of anticancer drugs. Advanced Drug Delivery Reviews. 2013; 65: $880-890$

[14] Thanki K, Gangwal RP, Sangamwar AT et al. Oral delivery of anticancer drugs: challenges and opportunities. Journal of Controlled Release. 2013; 170: 15-40 
[15] Bardelmeijer HA, van Tellingen O, Schellens JH et al. The oral route for the administration of cytotoxic drugs: Strategies to increase the efficiency and consistency of drug delivery. Investigational New Drugs. 2000; $18: 231-241$

[16] Varma MV, Khandavilli S, Ashokraj Y et al. Biopharmaceutic classification system: A scientific framework for pharmacokinetic optimization in drug research. Current Drug Metabolism. 2004; 5: 375-388

[17] Veber DF, Johnson SR, Cheng $\mathrm{H}-\mathrm{Y}$ et al. Molecular properties that influence the oral bioavailability of drug candidates. Journal of Medicinal Chemistry 2002; 45: 2615-2623

[18] Aungst BJ. Intestinal permeation enhancers. Journal of pharmaceutical sciences 2000; 89: 429-442

[19] Incecayir T, Tsume Y, Amidon GL. Comparison of the permeability of metoprolol and labetalol in rat, mouse, and Caco-2 cells: Use as a reference standard for BCS classification. Molecular Pharmaceutics. 2013; 10: 958-966

[20] Zur M, Gasparini M, Wolk O et al. The low/high BCS permeability class boundary: Physicochemical comparison of metoprolol and labetalol. Molecular Pharmaceutics. 2014; 11: 1707-1714

[21] Gupta D, Varghese Gupta S, Dahan A et al. Increasing oral absorption of polar neuraminidase inhibitors: A prodrug transporter approach applied to oseltamivir analogue. Molecular Pharmaceutics. 2013; 10: 512-522

[22] Cao F, Jia J, Yin Z et al. Ethylene glycol-linked amino acid diester prodrugs of oleanolic acid for PepT1-mediated transport: Synthesis, intestinal permeability and pharmacokinetics. Molecular Pharmaceutics. 2012; 9: 2127-2135

[23] Huber L. Validation of analytical methods. Agilent Technologies 2010; $13-28$
[24] Olfert ED, Cross BM, McWilliam AA. Guide to the care and use of experimental animals: Canadian council on animal care ottawa. vol 1 , 1993

[25] Islambulchilar Z, Ghanbarzadeh S, Emami S et al. Development and validation of an HPLC method for the analysis of sirolimus in drug products. Advanced Pharmaceutical Bulletin 2012; 2: 135-139

[26] Zakeri-Milani P, Valizadeh H, Azarmi Y et al. Simultaneous determination of metoprolol, propranolol and phenol red in samples from rat in situ intestinal perfusion studies. DARU Journal of Pharmaceutical Sciences 2006; 14: 102-108

[27] Salphati L, Childers K, Pan L et al. Evaluation of a single-pass intestinal-perfusion method in rat for the prediction of absorption in man. Journal of Pharmacy and Pharmacology 2001; 53: 1007-1013

[28] Song N-N, Li Q-S, Liu C-X. Intestinal permeability of metformin using single-pass intestinal perfusion in rats. World Journal of Gastroenterology 2006; 12: 4064

[29] Zakeri-Milani P, Valizadeh H, Islambulchilar Z et al. Investigation of the intestinal permeability of ciclosporin using the in situ technique in rats and the relevance of P-glycoprotein. Arzneimittel-Forschung 2008; 58 : 188-192

[30] Zakeri-Milani P, Valizadeh H, Tajerzadeh $\mathrm{H}$ et al. The utility of rat jejunal permeability for biopharmaceutics classification system. Drug Development and Industrial Pharmacy. 2009; 35: 1496-1502

[31] Suh KS, Goy A. Bortezomib in mantle cell lymphoma. Future Oncology 2008; 4: 149-168

[32] Zakeri-Milani P, Valizadeh $\mathrm{H}$, Tajerzadeh $\mathrm{H}$ et al. Predicting human intestinal permeability using single-pass intestinal perfusion in rat. Journal of Pharmacy and Pharmaceutical Siences 2007; 10: 368-379 